\title{
VOSEO, EL OTRO CASTELLANO DE AMÉRICA
}

\author{
Lizandro Angulo Rincón' \\ Universidad del Tolima, Tolima - Colombia \\ Grupo de investigación HISULA \\ langulo@ut.edu.co
}

Recepción: 28/02/2010

Evaluación: $12 / 03 / 2010$

Aceptación: 18/05/2010

Artículo de Reflexión

\section{RESUMEN}

Este artículo hace un recorrido por el origen, tipos y desarrollo del voseo, forma con la que se expresan las dos terceras partes de los habitantes del continente americano, con el propósito de reflexionar sobre la posibilidad de que se incorpore a la enseñanza en las escuelas y en la producción de contenidos de los medios de comunicación de las regiones que lo utilizan habitualmente y lo conciben como un fuerte elemento de identidad cultural. Con el estudio del voseo se quiere contribuir a la comprensión de un fenómeno lingüístico muy arraigado en América Latina y el Caribe, que amerita un reconocimiento mayor y una investigación permanente, toda vez que su evolución a pesar de las rígidas reglas del castellano tradicional de España se constituye en un acto de rebeldía y autonomía como el que expresaron nuestros próceres hace doscientos para darnos la independencia.

Palabras clave: Voseo, educación, América Latina y el Caribe, Medios de Comunicación.

\footnotetext{
1 Doctor en Comunicación y periodismo por la Universidad del País Vasco (España) Máster en Participación y desarrollo comunitario y especialista en Creación e innovación de medios de comunicación, también por la Universidad del País Vasco.
} 


\title{
THE 'VOSEO', THE OTHER CASTILIAN OF AMERICA
}

\author{
Lizandro Angulo Rincón \\ Universidad del Tolima- Colombia \\ HISULA Research Group \\ langulo@ut.edu.co
}

\begin{abstract}
This article covers the origin, types and development of the 'voseo', the second person singular form of address (as opposed to the Spanish second person plural form of address, N.d.T.) which two thirds of the Latin American inhabitants use. Its aims is to reflect about the possibility of introducing it into the teaching in schools and in the production of the contents in the media of the regions that use it regularly and view it as a strong element of cultural identity. Studying the 'voseo' contributes to understand a linguistic phenomenon deeply rooted in Latin America and the Caribbean that deserves a greater recognition and a continued research, since its development despite the rigid rules of traditional Castilian from Spain is taking the form of an act of rebellion and autonomy like the one our forefathers made to give us our independence two hundred years ago.
\end{abstract}

Key words: Voseo, Education, Latin America and the Caribbean, Media. 


\section{INTRODUCCIÓN}

El voseo, la forma particular que millones de personas de América Latina tienen para dirigirse a los demás fue reconocido por la Real Academia de la Lengua, con la publicación del Diccionario panhispánico de dudas. ${ }^{2}$ Vale decir que esa decisión es justa porque, primero, se acepta que no hay un único castellano, ${ }^{3}$ el de España, sino que, como lo afirma Ernesto Sábato, ${ }^{4}$ existen muchos otros dispersos en la vasta geografía de América; segundo, se concibe a un castellano rico que se desarrolla independientemente de las rígidas fórmulas lingüísticas de la península ibérica y, tercero, se le da razón a muchas personas que sin ningún complejo usan el voseo pronominal (vos) y verbal (venís, tenéis, corrés, camináis, jugás) para relacionarse con sus semejantes.

Anteriormente, el tratamiento de vos era considerado un error, como se comprueba en el libro Dialectología española, de Alonso Zamora Vicente:

Vos ha reemplazado al de segunda persona del singular, tú, olvidado. Con él se ha perdido igualmente os, pronombre objeto, y el posesivo vuestro, que han sido reemplazados, respectivamente, por te, tuyo, tu. Este uso de los pronombres acarrea frases híbridas al ser equivocado algunas veces el oportuno uso de las formas verbales. ${ }^{5}$

La complejidad del tema del voseo, como señala la investigadora Norma Beatriz Carriburo, proviene de que como nunca se lo tomó más que como una forma agramatical o incorrecta, o en el mejor de los casos un arcaísmo, no hubo ni hay una preceptiva sobre esa manera de expresarse.

A raíz de la publicación del Diccionario panhispánico de dudas en el 2005 han aparecido diversos escritos en los que se analiza la trascendencia del voseo como elemento constitutivo de la lingüística española. En ellos también se enumeran los posibles orígenes del pronombre vos y las variantes de su empleo en los países de América Latina y el Caribe.

2 REAL ACADEMIA ESPAÑOLA \& ASOCIACIÓN DE ACADEMIAS DE LA LENGUA ESPAÑOLA. (2005): Diccionario panhispánico de dudas. Madrid, Santillana Ediciones Generales, p. 34.

3 Preferimos el término castellano en lugar de español, porque en España además del castellano se hablan el euskera en la comunidad autónoma del País Vasco, el gallego en la comunidad de Galicia, el catalán en las comunidades de Cataluña, Islas Baleares y Valencia, y el bable en la comunidad de Asturias. Este último se habla escasamente.

4 SÁBATO, Ernesto. (1966): "El Voseo", en Revista Cuaderno Cultural. № 6, año 4, Madrid, Departamento Cultural de la Embajada Argentina, pp. 43-45.

5 ZAMORA, Alonso.(1974): Dialectología española. Madrid, Editorial Gredos, S.A, p. 54 . 
Para la redacción de este artículo se ha estudiado una gran cantidad de textos provenientes de las más diversas vertientes lingüísticas, los cuales se han condensado en varios párrafos. Esto nos ha servido para una comprensión más amplia del fenómeno del voseo (Colombia), que incluye su origen, desarrollo $\mathrm{y}$ futuro.

Nuestra intención no es otra que la de efectuar un pequeño aporte que estimule a las nuevas generaciones de educadores, poetas, periodistas, profesores y escritores a profundizar en la raíces lingüísticas del castellano. Así las cosas, para la lectura de este escrito hemos establecido el siguiente mapa de navegación:

1. Origen, desarrollo y significado social del voseo.

2. Clases de voseo y variantes en función del pronombre y del verbo.

3. Variantes del voseo en Latinoamérica y el Caribe.

4. Reflexiones sobre el uso del voseo en el sector educativo y en los medios de comunicación.

5. Conclusiones y bibliografía.

\section{Origen, Desarrollo y Significado Social del Voseo}

Según la investigadora Norma Beatriz Carricaburo, ${ }^{6}$ el pronombre vos se empleaba a partir del siglo IV d.C. y connotaba sumo respeto cuando un hablante se dirigía a su interlocutor, pero su uso exacto se ciñe al trato con el emperador. Para sus inicios, se apuntan dos causas:

- La presencia de dos emperadores puesto que el imperio romano ${ }^{7} \mathrm{se}$ había dividido, lo cual pudo inducir el uso del vos como una forma de incluirlos a ambos. ${ }^{8}$

6 CARRICABURO, Norma Beatriz.(2000): “Algunas peculiaridades morfosintácticas del Español de la Argentina”, en Español actual: Revista de Español Vivo, edición 74, pp. 25-36.

7 El imperio romano es un periodo de la historia de Roma caracterizado por un régimen político dominado por un emperador, que comprende desde el 27 a.C. hasta su disolución en el 476 d.C. En pleno apogeo alcanzó una extensión desde el océano Atlántico al oeste hasta las orillas del Mar Negro, el Mar Rojo y el Golfo Pérsico al este, y desde el desierto del Sahara al sur hasta las costas boscosas a orillas de los ríos Rin y Danubio y la frontera con Caledonia.

8 En este caso podríamos deducir, aunque sin tener una certeza plena, de que el vos era

la síntesis de una expresión como "nosotros dos". De tal modo, los emperadores romanos,

al parecer, se nombraban como representantes del imperio. 
- El vos nació como respuesta al nos, ${ }^{9}$ fórmula por la que el emperador romano se mencionaba a sí mismo como representante del poder y cabeza de todo el imperio.

En España el vos se utilizaba en lugar del vosotros (segunda persona del plural), aunque en otros casos también hacía referencia a la segunda persona del singular. La expansión de este pronombre se hizo más compleja hasta los siglos VI y VII y fue decayendo hasta desaparecer entre los siglos XVI y XVII. Las lenguas romances, esto es, derivadas del latín le daban los siguientes valores para el tratamiento con el vos: (1) tratamiento para más de un interlocutor considerado de más autoridad; (2) tratamiento para un interlocutor del que se espera un favor o beneficio; y (3) tratamiento impersonal formal (no afectivo) con un solo interlocutor.

De manera que en sus inicios y desarrollo (siglos VIII y XIV) el vos tuvo una connotación de solemnidad, nobleza, distinción o de trato respetuoso hacia una persona investida de mayor autoridad o rango, pero en los siglos XV y XVI había confusión en España entre el uso del tú y del vos. La causa de ello fue la aparición de la expresión que dio origen al usted, es decir, vuestra merced y sus formas intermedias como vuasted, vuested y vusted ${ }^{10}$ Eso condujo a que al aparecer usted como fórmula de respeto, se fuera realizando un largo desgaste del vos durante el siglo XVI, que descendió de su condición hidalga a una nueva, plebeya o vulgar. En compensación, el tú, que en la España del 1500 era el tratamiento que se daba a los inferiores o entre iguales cuando había máxima intimidad, recobró terreno a costa del vos en el coloquio familiar, ${ }^{11}$ hasta eliminarlo durante el siglo XVII y quizá parte del XVIII. ${ }^{12}$

El vos, como hemos dicho, fue rebajándose de dignidad, y así se refleja en algunos testimonios excepcionales en El quijote de la mancha: "finalmente con una no vista arrogancia llamaba de vos a sus iguales y a los mismos que le

9 Cabe anotar que siglos después el nos y el vos se convirtieron en pronombres del castellano referidos a la primera y segunda persona del plural, respectivamente, pero desde mediados del siglo XVI se les agregó la palabra -otros para convertirlos en los pronombres que hoy se conocen como nosotros y vosotros.

${ }^{10} \mathrm{El}$ arcaísmo vusted aún se utiliza en el habla campesina del altiplano cundiboyacense colombiano, y se constituye en una fórmula intermedia entre el pronombre usted y el posesivo vuestro.

11 En España aún quedan reminiscencias del voseo. Así lo atestigua Idurre Aldama, trabajadora vasca, quien aún escucha a sus abuelos tratarse de vos.

12 ZAMORA, Alonso. (1974): Dialectología española. . Madrid, España, Editorial Gredos, S.A y LAPESA, Rafael (1980). Historia de la lengua española. . Madrid, España, Editorial Gredos S.A. 
conocían" (I, cáp. LI); “desdichadas de nosotras las dueñas... no dejaran de echarnos un vos nuestras señoras si pensasen por ello ser reinas" (II, cáp. XL).

El paso del tratamiento de vos a tú, o viceversa, también se da en el español medieval en una misma frase o en frases inmediatas, situación que en no pocas oportunidades se prestó a confusión. En El cantar del Mio Cid es ya evidente ese caos como lo demuestra la frase: "mientra que visquiéredes bien se fará lo to" ("mientras viviereis, lo tuyo saldrá bien"), con verbo en plural y posesivo de un poseedor, antecedente del primer ejemplo americano conocido, que es un "façételo vos" de Bernal Díaz del Castillo. ${ }^{13}$

De todos modos, es innegable el origen latino del vos, ya que se encuentra presente en las lenguas romances. En el francés vous (vosotros, ustedes), el portugués você (tú, usted en el portugués brasileño), el rumano ${ }^{14}$ voi (vosotros), el catalán arcaico vos sabeu (vos sabéis) o vostès (usted) y el italiano voi (vosotros, ustedes).

\section{Clases de Voseo y Variantes en Función del Pronombre y del Verbo}

El apartado sobre el origen y el significado social del voseo lleva a la conclusión de que esta forma de expresarse tiene dos clases: el voseo reverencial y el voseo dialectal americano.

\section{EI voseo reverencial}

Como se anotó anteriormente esta clase de voseo se utilizaba en el pasado. Actualmente se emplea con algunos grados y títulos en actos solemnes, o en textos literarios que reflejan el lenguaje de otras épocas, por ejemplo, la expresión "en vos confio". El posesivo es vuestro, vuestra. Vos es segunda persona del gramatical tanto del singular como del plural.

\section{El voseo dialectal americano}

Esta clase de voseo es el que se usa para dirigirse a un solo interlocutor. Existe en América expresado con variantes derivadas de las condiciones regionales y sociales $\mathrm{y}$, al contrario de lo que sucede con el reverencial, el dialectal americano connota acercamiento y familiaridad.

\footnotetext{
13 LAPESA, Rafael. (1981): "El español de América”, en Lapesa: pp.535-602.

${ }^{14}$ Los rumanos no tienen el pronombre vos como segunda persona del singular. En cambio sí tienen el usted (dumneata) y el ustedes (dumneavoastrâ).
} 
En América el voseo pronominal (vos) corresponde a la segunda persona del singular en reemplazo del tú y ti, y en el trato informal el pronombre adopta varios usos:

- Como sujeto: vos tenés muchas cosas buenas.

- Como vocativo: ¿por qué lo complicás todo?

- Como término de preposición: cada vez que sale con vos.

- Como término de comparación: es tan noble como vos.

Sin embargo sólo se da en algunos tiempos del castellano, puesto que en otros adopta los verbos y posesivos del tuteo, como lo indican la Real Academia de la Lengua y la Asociación de Academias de la Lengua Española: ${ }^{15}$ "para el pronombre átono (el que se usa con los verbos pronominales y en los complementos sin preposición) y para el posesivo, se emplean las formas de tuteo te (para objetos directos e indirectos) y tú, tuyo, respectivamente : cómo te odio a vos, no abrás la boca.

El voseo verbal en América consiste en el empleo de las desinencias verbales propias de la segunda persona del plural (vosotros) con algunas modificaciones, para las conjugaciones verbales de la segunda persona del singular (vos). En este continente, no obstante, las variantes son constantes en función de las condiciones geográficas y sociales de los hablantes, lo que hace que no todas las expresiones estén aceptadas en la norma culta. ${ }^{16}$ En algunas regiones -como se verá más adelante ${ }^{17}$ el verbo de la conjugación voseante cambia de las formas monoptongadas (hablás, tenés) a las formas diptongadas, dependiendo del tiempo (habláis, tenéis). En la siguiente tabla se resumen las formas que adopta el voseo de acuerdo con los tiempos del castellano en los que aplica.

\footnotetext{
${ }^{15}$ Ibídem, p. 2.

${ }^{16}$ Por ejemplo, en el pretérito perfecto simple es usual que la conjugación correcta de los verbos posea la $s$ intermedia (volviste, trabajaste...), lo cual corresponde a la norma culta. Claro que en algunas regiones es frecuente la conjugación vulgar de los verbos en ese tiempo con el anexo de un $s$ al final -o desinencia de la segunda persona con $s$ analógica- (volvistes, trabajastes...), como también la supresión de la $s$ intermedia (volvites, trabajates...).

${ }^{17} \mathrm{Al}$ igual que con los verbos monoptongados, los verbos con diptongo también presentan cambios que los hace oscilar entre la expresión vulgar y la norma culta. Por ejemplo, es usual la aspiración de la $s$ en las conjugaciones del presente indicativo (sabéis por sabéi) o la eliminación de la vocal abierta (sabéis por sabis).
} 
Tabla 1. Formas del Voseo Verbal por Países

\begin{tabular}{|c|c|c|c|c|c|c|c|c|}
\hline $\begin{array}{l}\text { País / } \\
\text { Tiempo } \\
\text { verbal }\end{array}$ & $\begin{array}{c}\text { Presente de } \\
\text { indicativo }\end{array}$ & $\begin{array}{c}\text { Pretérito } \\
\text { imperfecto } \\
\text { de indicativo } \\
\text { p copretérito }\end{array}$ & \begin{tabular}{|c|} 
Pretérito \\
perfecto \\
simple o \\
pretérito de \\
indicativo \\
\end{tabular} & $\begin{array}{l}\text { Futuro de } \\
\text { indicativo }\end{array}$ & $\begin{array}{c}\text { Presente de } \\
\text { subjuntivo }\end{array}$ & \begin{tabular}{|l|} 
Pretérito \\
imperfecto o \\
pretérito de \\
subjuntivo
\end{tabular} & \begin{tabular}{|c|} 
Condicional \\
0 \\
pospretérito
\end{tabular} & Imperativo \\
\hline Argentina & $\begin{array}{l}\text { cantás } \\
\text { comés } \\
\text { vivís }\end{array}$ & & \begin{tabular}{|c|} 
cantastes \\
comistes \\
vivistes [1]
\end{tabular} & & $\begin{array}{c}\text { cantés } \\
\text { comás } \\
\text { vivás [2] }\end{array}$ & & & $\begin{array}{l}\text { cantá } \\
\text { comé } \\
\text { viví }\end{array}$ \\
\hline Paraguay & $\begin{array}{l}\text { cantás } \\
\text { comés } \\
\text { vivís }\end{array}$ & & \begin{tabular}{|c|} 
cantastes \\
comistes \\
vivistes [1]
\end{tabular} & & $\begin{array}{c}\text { cantés } \\
\text { comás } \\
\text { vivás [2] }\end{array}$ & & & $\begin{array}{l}\text { cantá } \\
\text { comé } \\
\text { viví }\end{array}$ \\
\hline Uruguay & $\begin{array}{l}\text { cantás } \\
\text { comés } \\
\text { vivís }\end{array}$ & & \begin{tabular}{|c|} 
cantastes \\
comistes \\
vivistes [7] \\
\end{tabular} & & $\begin{array}{c}\text { cantés } \\
\text { comás } \\
\text { vivás [2] }\end{array}$ & & & $\begin{array}{l}\text { cantá } \\
\text { comé } \\
\text { viví }\end{array}$ \\
\hline Chile & $\begin{array}{l}\text { cantái(s) } \\
\text { comí(s) } \\
\text { viví(s) }\end{array}$ & $\begin{array}{c}\text { cantabai(s) } \\
\text { comíai(s) } \\
\text { vivíai(s) }\end{array}$ & \begin{tabular}{|c|} 
cantastes \\
comistes \\
vivistes [7]
\end{tabular} & $\begin{array}{c}\text { cantarí(s) } \\
\text { comerí(s) } \\
\text { vivirí(s) } \\
\end{array}$ & $\begin{array}{l}\text { cantí(s) } \\
\text { comái(s) } \\
\text { vivái(s) }\end{array}$ & \begin{tabular}{|c|} 
cantarai(s) \\
comierai(s) \\
vivierai(s) \\
\end{tabular} & $\begin{array}{c}\text { cantaríai(s) } \\
\text { comeríai(s) } \\
\text { viviríai(s) } \\
\end{array}$ & \\
\hline $\begin{array}{c}\text { Perú } \\
\text { (Arequipa) }\end{array}$ & $\begin{array}{l}\text { cantás } \\
\text { comís } \\
\text { vivís }\end{array}$ & & $\begin{array}{c}\text { cantastes } \\
\text { comistes } \\
\text { vivistes } \\
\end{array}$ & $\begin{array}{c}\text { cantarás } \\
\text { comerís } \\
\text { vivirís }\end{array}$ & & & & $\begin{array}{l}\text { cantá } \\
\text { comé } \\
\text { viví }\end{array}$ \\
\hline Bolivia & $\begin{array}{c}\text { cantáis/ } \\
\text { cantás } \\
\text { coméis/ } \\
\text { comés } \\
\text { vivís [3] }\end{array}$ & & & & $\begin{array}{c}\text { cantés } \\
\text { comás } \\
\text { vivás [4] }\end{array}$ & & & $\begin{array}{l}\text { cantá } \\
\text { comé } \\
\text { viví [4] }\end{array}$ \\
\hline Ecuador & \begin{tabular}{|c|} 
cantás/ \\
cantáis \\
comés/comís \\
vivís [5]
\end{tabular} & & & $\begin{array}{l}\text { cantarís } \\
\text { comerís } \\
\text { vivirís [6] }\end{array}$ & & & & $\begin{array}{l}\text { cantá } \\
\text { comé } \\
\text { viví }\end{array}$ \\
\hline Colombia & $\begin{array}{l}\text { cantás } \\
\text { comés } \\
\text { vivís }\end{array}$ & & $\begin{array}{c}\text { cantastes/ } \\
\text { cantates } \\
\text { comistes/ } \\
\text { comites } \\
\text { vivistes/ } \\
\text { vivites [7] }\end{array}$ & $\begin{array}{c}\text { cantarés } \\
\text { comerés } \\
\text { vivirés [8] }\end{array}$ & $\begin{array}{l}\text { cantés } \\
\text { comás } \\
\text { vivás }\end{array}$ & & & $\begin{array}{l}\text { cantá } \\
\text { comé } \\
\text { viví }\end{array}$ \\
\hline Venezuela & $\begin{array}{l}\text { cantáis/ } \\
\text { cantás } \\
\text { coméis/ } \\
\text { comés } \\
\text { vivís [9] }\end{array}$ & & $\begin{array}{c}\text { cantastes/ } \\
\text { cantates } \\
\text { comistes/ } \\
\text { comites } \\
\text { vivistes/ } \\
\text { vivites [9] } \\
\end{array}$ & $\begin{array}{c}\text { cantaréis/ } \\
\text { cantarés } \\
\text { comeréis/ } \\
\text { comerés } \\
\text { viviréis/ } \\
\text { vivirés [9] }\end{array}$ & & & & $\begin{array}{c}\text { cantá } \\
\text { comé } \\
\text { viví [10] }\end{array}$ \\
\hline Guatemala & $\begin{array}{l}\text { cantás } \\
\text { comés } \\
\text { vivís }\end{array}$ & & \begin{tabular}{|c|} 
cantastes \\
comistes \\
vivistes [7]
\end{tabular} & $\begin{array}{l}\text { cantarés } \\
\text { comerés } \\
\text { vivirés }\end{array}$ & $\begin{array}{c}\text { cantés } \\
\text { comás } \\
\text { vivás [11] }\end{array}$ & & & $\begin{array}{l}\text { cantá } \\
\text { comé } \\
\text { viví }\end{array}$ \\
\hline El Salvador & $\begin{array}{l}\text { cantás } \\
\text { comés } \\
\text { vivís }\end{array}$ & & \begin{tabular}{|c|} 
cantastes \\
comistes \\
vivistes [7] \\
\end{tabular} & $\begin{array}{l}\text { cantarés } \\
\text { comerés } \\
\text { vivirés }\end{array}$ & $\begin{array}{c}\text { cantés } \\
\text { comás } \\
\text { vivás [11] }\end{array}$ & & & $\begin{array}{l}\text { cantá } \\
\text { comé } \\
\text { viví }\end{array}$ \\
\hline Honduras & $\begin{array}{l}\text { cantás } \\
\text { comés } \\
\text { vivís }\end{array}$ & & $\begin{array}{c}\text { cantastes } \\
\text { comistes } \\
\text { vivistes [1] }\end{array}$ & $\begin{array}{c}\text { cantarés } \\
\text { comerés } \\
\text { vivirés [8] } \\
\end{array}$ & $\begin{array}{c}\text { cantés } \\
\text { comás } \\
\text { vivás [11] }\end{array}$ & & & $\begin{array}{l}\text { cantá } \\
\text { comé } \\
\text { viví }\end{array}$ \\
\hline Nicaragua & $\begin{array}{l}\text { cantás } \\
\text { comés } \\
\text { vivís }\end{array}$ & & $\begin{array}{l}\text { cantastes } \\
\text { comistes } \\
\text { vivistes }\end{array}$ & & $\begin{array}{l}\text { cantés } \\
\text { comás } \\
\text { vivás }\end{array}$ & & & $\begin{array}{l}\text { cantá } \\
\text { comé } \\
\text { viví }\end{array}$ \\
\hline Costa Rica & $\begin{array}{l}\text { cantás } \\
\text { comés } \\
\text { vivís }\end{array}$ & & & & $\begin{array}{l}\text { cantés } \\
\text { comás } \\
\text { vivás }\end{array}$ & & & $\begin{array}{l}\text { cantá } \\
\text { comé } \\
\text { viví }\end{array}$ \\
\hline Panamá & $\begin{array}{c}\text { cantái(s) } \\
\text { coméi(s) } \\
\text { vivís } \\
\end{array}$ & & & & & & & $\begin{array}{c}\text { cantá } \\
\text { comé } \\
\text { viví [12] }\end{array}$ \\
\hline $\begin{array}{c}\text { México } \\
\text { (Chiapas y } \\
\text { Tabasco) }\end{array}$ & $\begin{array}{l}\text { cantás } \\
\text { comés } \\
\text { vivís }\end{array}$ & & $\begin{array}{l}\text { cantastes } \\
\text { comistes } \\
\text { vivistes }\end{array}$ & $\begin{array}{c}\text { cantarés } \\
\text { comerés } \\
\text { vivirés }\end{array}$ & & & & $\begin{array}{l}\text { cantá } \\
\text { comé } \\
\text { viví }\end{array}$ \\
\hline $\begin{array}{c}\text { Cuba } \\
\text { (Oriente) }\end{array}$ & $\begin{array}{c}\text { cantái(s) } \\
\text { coméis(s) } \\
\text { vivís }\end{array}$ & & & $\begin{array}{c}\text { cantaréi(s) } \\
\text { comeréi(s) } \\
\text { viviréi(s) }\end{array}$ & & & & $\begin{array}{l}\text { cantá } \\
\text { comé } \\
\text { viví }\end{array}$ \\
\hline
\end{tabular}

Fuente: Real Academia de la Lengua y Asociación de Academias de la Lengua Española.

Rhela. Vol. 14. Año 2009, pp. $267-288$ 
[1] Alternan en el uso con las formas de tuteo cantaste, comiste, viviste, únicas aceptadas en la norma culta.

[2] Alternan en el uso con las formas de tuteo cantes, comas, vivas, únicas aceptadas en la norma culta.

[3] La primera forma es la propia de la zona colla (oeste y sur del país); la segunda, de la zona camba (este y norte del país).

[4] Solo se emplean en la zona camba. En la zona colla se usan las formas de tuteo cantes, comas vivas (subjuntivo) y canta, come, vive (imperativo).

[5] La primera forma es la propia de la costa y de Esmeraldas; la segunda, de la sierra.

[6] Solo se emplean en la sierra. En la costa y en Esmeraldas se usan las formas de tuteo cantarás, comerás, vivirás.

[7] Alternan en el uso con las formas de tuteo cantaste, comiste, viviste.

[8] Alternan en el uso con las formas de tuteo cantarás, comerás, vivirás.

[9] La primera forma es zuliana; la segunda, andina. En el futuro andino alternan las formas de voseo en -rés y las de tuteo en -rás.

[10] Solo se emplean en Zulia. En la zona andina se usan las formas de tuteo canta, come, vive.

[11] Alternan en el uso con las formas de tuteo cantes, comas, vivas.

[12] Alternan en el uso con las formas de tuteo canta, come, vive.

Como se observa en la tabla anterior, el voseo tiene usos diversos pues algunos países de América Latina bien sea por las condiciones geográficas o diastráticas (fenómenos lingüísticos relacionados con el nivel sociocultural de los hablantes) han creados tres modalidades para expresarlo según las normas del voseo pronominal y verbal:

- Voseo exclusivamente verbal: Tú tenés cinco años, no cuatro (Uruguay).

- Voseo exclusivamente pronominal: vos tienes la culpa (Bolivia).

- Plenamente voseante: vos sos muy bueno.

- Una descripción más amplia de estas modalidades, conforme al país o región, se expone en el siguiente epígrafe.

\section{Variantes del voseo en América Latina y el Caribe}

Decir que el voseo desaparecerá en América es un craso error, pues la vida cotidiana de sus gentes evidencia un trato frecuente del vos y de su conjugación monoptongada o diptongada. Es más, según María Vaquero, ${ }^{18}$ las 2/3 partes de la población de América vosea, lo cual se constituye en un fenómeno profundamente enraizado en el lenguaje y cultura de los que habitan este continente.

18 VAQUERO, María. (1996): "El español de América". en Cuadernos de Lengua Española: Tomo II. Madrid, Arco Libros S.A pp. 22-26, 28. 
En ese contexto lo más importante no es declarar -como los gramáticos agoreros de España lo hacían antes de la publicación del Diccionario panhispánico de dudas- la incorrección del voseo $\mathrm{y}$, por ende, vaticinar su desaparición, sino conocer por qué razón se quedó en América después de la conquista.

Para una mejor comprensión del fenómeno lingüístico del voseo es necesario indagar sobre cuáles fueron las razones para que esta forma de expresión se quedara en América, a pesar de que en la madre patria el tratamiento de tú fue la regla después del siglo XVI. Todo parece indicar que por encontrarse España a miles de kilómetros no todos los cambios llegaron a sus colonias, entre ellos los cambios en las formas de tratamiento. Desde esa premisa, pues, se pueden establecer dos hipótesis sobre la permanencia del voseo en América.

La primera asocia el voseo americano con el fenómeno de la hidalguización. ${ }^{19} \mathrm{Al}$ respecto Urdaneta señala:

Como resultado de la conquista, todos los que llegaron a América se sintieron como señores y adoptaron los usos y las costumbres lingüísticas de las capas sociales superiores. El hecho de que el voseo se encuentra en las regiones que fueron integradas al proceso colonizador en la primera mitad del siglo XVI, se entiende como un apoyo a la tesis de la hidalguización. ${ }^{20}$

Lo que quiere decir Urdaneta es que los conquistadores españoles deseaban sentirse como nobles y aristócratas en las nuevas tierras y, para ello, emplearon el voseo -que en España antes de los siglos XVI o XVII era el trato respetuoso que se dispensaba a gente distinguida o con alcurnia- para transmitir a los americanos y a ellos mismos la sensación de ser gente importante.

La segunda afirma que las regiones que tenían una comunicación más fluida con la metrópoli y, por tanto, vínculos más estrechos con ella recibían los cambios que allí se gestaban con mucha más rapidez. Ese fue el caso de Perú y México, sedes de cortes virreinales y centros culturales que enlazaban al nuevo y al viejo mundo, y de República Dominicana, donde se construyó la

\footnotetext{
19 La palabra hidalgo tiene dos acepciones: de ánimo generoso y noble y persona que por su sangre es de una clase noble y distinguida. En el contexto que nos ocupa, utilizamos la segunda acepción para referirnos a los conquistadores españoles que quisieron ser señores o nobles en América empleando para ello el voseo que, como hemos señalado, correspondía al trato reverencial o entre nobles en la Península Ibérica antes del siglo XVI.

${ }^{20}$ URDANETA, I.P. (1981): Historia y geografia hispanoamericana del voseo. Caracas, la Casa de Bello.
} 
afamada Universidad de Santo Domingo, regiones todas ellas que, junto a Cuba y Puerto Rico, rehabilitaban el tú y rechazaban el vos por la influencia de los españoles. De ahí que actualmente esos países, salvo pequeñas excepciones, sean fundamentalmente tuteantes.

Por el contrario, las zonas que no tuvieron el influjo político-cultural anterior y su vida era más rústica, como América Central, Colombia y Venezuela, sierra ecuatoriana, Chile y Río de la Plata prefirieron el vos, con distinta intensidad y no en todas las formas pronominales.

\section{El voseo en Argentina}

Los habitantes de España y toda Europa pensaban que los únicos que voseaban eran los argentinos, debido a que muchos textos literarios y mediáticos se evidencia el uso natural y desenfadado del vos, y de los verbos monoptongados en la mayoría de los casos. Sin embargo, con la sostenida emigración de ecuatorianos, colombianos y bolivianos en los últimos 20 años a la Península Ibérica, los españoles no dejan de sorprenderse con la variedad de expresiones que se derivan del voseo.

A pesar de ello, Argentina sigue siendo el paradigma dominante debido a varias razones. Una de ellas, y quizás una de las más trascendentales, es que en 1982 la Academia Argentina de Letras fue la primera en Iberoamérica en aceptar el voseo como norma culta. En esa época la academia sentenció: "reconocer como legítimo el empleo del voseo siempre y cuando se conserve dentro de los límites que impone el buen gusto, esto es, huir tanto de la afectación como del vulgarismo." 21

Es decir, los gramáticos argentinos consideraron que esa forma particular de dirigirse a un interlocutor era válida tanto en el trato informal como en la correspondencia, la literatura y los textos oficiales. Tal decisión implicó que en la década de los 80 las escuelas argentinas comenzaran a enseñar los pronombres yo, vos (en reemplazo del tú), él-ella, nosotros, ustedes (en reemplazo del vosotros), ellos-ellas, en lugar de los tradicionales yo, tú, él-ella, nosotros, vosotros, ellos, que todavía se enseñan en América Latina.

Otra de las razones para la ponderación del vos en la Argentina hay que buscarla en 1810, año de la independencia de este país. El argentino Domingo

${ }^{21}$ BOLETÍN DE LA ACADEMIA ARGENTINA DE LETRAS XLVII. (1982), Buenos Aires, Academia Argentina de Letras. 
Faustino Sarmiento (1881-1888), fue uno de los personajes ilustres de la época que promulgó la independencia lingüística de su país con respecto a España, pues consideraba que esta última no era creadora de una verdadera cultura. Sarmiento miraba hacia Inglaterra, Francia y Estados Unidos, y defendía la posibilidad de que las nuevas naciones latinoamericanas crearan una lengua independiente de las estrictas normas de la Real Academia de la Lengua Española, formaran sus propias palabras, asimilaran expresiones populares y aceptaran préstamos de los idiomas indígenas. ${ }^{22}$

En 1966 Ernesto Sábato también se rebeló contra los lingüistas de la Península Ibérica, cuando molesto por la afirmación de los visitantes españoles según la cual los argentinos hablan mal el castellano, escribió:

¿Y qué? Sólo los viejos gramáticos siguen suponiendo que hay una lengua cristalizada, un dechado supremo al que deben ajustarse los hablantes vivan donde vivan. Y esta curiosa superchería tiene tanto prestigio que cada cierto tiempo tenemos que soportar aquí la insolencia de cualquier extranjero que (en un castellano balbuceante y grosero) nos acuse, apenas desembarcado, de no hablar bien el castellano. Idea, calor, que le inyectó en alguna academia de Zürich o Londres un español que sigue creyendo en el mito.

El voseo más puro de Argentina, esto es, el que posee el voseo pronominal $\mathrm{y}$ el verbal proviene fundamente de la provincia de Buenos Aires. ${ }^{23}$ En otras regiones, aunque con poca intensidad, se usa el voseo pronominal con verbos del pronombre tú (vos amas, vos tienes...), mientras que en las provincias de Mendoza, San Luis y San Juan es común escuchar el voseo chileno (vos sabéis, tenéis...). Este fenómeno se debe a que las tres regiones dependieron de Chile hasta 1776, año en el que se creó el Virreinato de la Plata, y se incorporaron a Buenos Aires por considerarlas dentro de sus fronteras naturales. ${ }^{24}$

\section{El voseo en Chile y Perú}

El voseo en Chile se da en el ámbito coloquial, pero en el familiar se emplea el tú. Tangencialmente se encuentra en los planes de estudio escolares y

\footnotetext{
22 MALBERG, B. (1970): La América hispanohablante. Madrid, ediciones Itsmo.

${ }^{23}$ En entrevista realizada a la periodista bonaerense Greta Frankenfeld Roca, radicada en Bilbao (España), la profesional sostuvo que el voseo se utiliza en todas las clases sociales y que el trato con tú les suena a 'telenovela', o sea, las personas que lo utilizan pasan por arribistas. En Argentina, no obstante, existe confusión entre los términos voseo y tuteo, en el sentido de que cuando un argentino desea que lo traten de vos usualmente dice "por qué no me tuteas", en vez de "por qué no me voseas".

24 ZAMORA, Alonso. (1974): Dialectología española. . Madrid, España, Editorial Gredos, S.A, p 56.
} 
escasamente en algunos textos literarios. Este tipo de voseo es fundamentalmente verbal, es decir, combina el pronombre tú con verbos diptongados (tenéis, estudiáis), y en muchos casos -sobre todo en el habla vulgar- es corriente que se presenten derivaciones espurias como:

- La pérdida de $s$ en las formas terminadas en áis: cantái, comái.

- Cambio de éis por ís (pérdida de la vocal abierta o mantenimiento de $i s$ ): tú o vos comís.

- Prevalencia de expresiones como tú erís, en vez de tú eres, y tú soi en lugar de vos sois.

- El escritor y político venezolano, Andrés Bello (1781-1865), quien estuvo radicado gran parte de su vida en Chile, combatió el voseo ${ }^{25}$ a tal punto que en el siglo XIX esa variante del castellano fue desterrada de las clases educadas. En el siglo XX resurgió aunque en el habla coloquial, como anotamos anteriormente.

En Perú el tuteo es el habla generalizada, debido a que fue uno de los países que más rápido asimiló el cambio del vos al tú en España. El voseo se da en el norte y en el sur, o sea, en zonas limítrofes con naciones voseantes. En el norte, en las poblaciones de Ancash, San Martín, Huanuco y Cajamarca, se escucha el voseo pronominal con tuteo verbal (vos tienes), y en el sur, en la ciudad de Arequipa, junto al vos se usan las desinencias verbales chilenas.

\section{El voseo en Uruguay y Paraguay}

En Uruguay y en Paraguay el voseo se ciñe a las normas del voseo Argentino. Los tres países forman el eje del Río de la Plata en el que es común el voseo pronominal (vos) y el voseo verbal monoptongado (venís, tenés...).

En Paraguay el tratamiento de vos es corriente en todas las capas de la sociedad, aunque esa forma de expresión coexiste con el guaraní, idioma oficial como también lo es el castellano. En Uruguay se rige por la norma rioplatense, salvo en Montevideo la capital donde es muy frecuente el pronombre tú acompañado por el voseo solamente verbal: ${ }^{26}$ tú tenés cinco años.

25 El biólogo marino chileno, Guillermo Aravena, manifestó en entrevista realizada en el 2006 que en su país el voseo es utilizado por las clases populares y, en general, es catalogado como incorrecto. Enfatiza que entre los intelectuales es considerado vulgar. $\mathrm{Su}$ incorrección se atribuye tanto a las conjugaciones como a las usuales aspiraciones de la $s$, tanto en el pronombre ' $v o$ ' como en los verbos 'sabéi, tenéi', etc.

${ }^{26}$ Rubén Ruiz, trabajador uruguayo, señala que el sujeto vos se emplea en expresiones coloquiales como che, vos. La palabra che es de origen indígena y su significado es $m i$ (posesivo). De ahí frases como che señor (mi señor). Actualmente, che, según la Real Academia de la Lengua (2001), se emplea para llamar, pedir o detener la atención de alguien, o para denotar asombro o sorpresa. 


\section{El voseo en Bolivia}

En Bolivia el voseo se da tanto en la norma culta como en la expresión popular, y convive con otros idiomas oficiales diferentes del castellano como el quechua (hablado por el $25 \%$ de los indígenas) y el aimara (hablado por el $20 \%$ de los nativos).

El voseo pronominal y verbal al estilo vos tenés se utiliza fundamentalmente en la zona camba, es decir, en el norte y este del país, donde está ubicada Santa Cruz de la Sierra, una de las ciudades más ricas en recursos naturales y mineros. Para los cruceños el voseo se constituye en orgullo regional, señal de la fuerte identidad del camba, en tanto que el tú es mal visto, y el usted se usa para el trato respetuoso y formal. ${ }^{27}$

La zona andina, donde se encuentran poblaciones como Oruro, Potosí, Tarija y Cochabamba, se caracteriza por la confusión de formas pronominales y verbales de tuteo y voseo: ${ }^{28}$ vos hablas, y en algunos casos, sobre todo en el sur, se escuchan verbos diptongados (habláis, estudiáis...), debido a su cercanía con Chile.

\section{EI voseo en Colombia, Venezuela y Ecuador}

El Diccionario Panhispánico de Dudas dice que en Colombia se vosea en forma generalizada en Antioquia y entre el pacífico y el río Cauca, ${ }^{29}$ así como en Bogotá, aunque en la capital es usual que haya confusión entre el tuteo y el voseo. Lamentablemente el diccionario no hace alusión alguna al voseo de la provincia de Ocaña, ${ }^{30}$ donde se da en estado puro y se constituye en un pilar de

27 LAPESA, Rafael. (1970): Las formas verbales de segunda persona y los orígenes del voseo. Actas del Tercer Congreso de Hispanistas. Coord. Por Carlos H. Magis, México, p. 519.

28 VARGAS, Dino, natural de Cochabamba (Bolivia), confirma que en el altiplano es usual el uso del vos con verbos pertenecientes al tú. Por ejemplo, vos tienes.

29 Esa región comprende los departamentos de Antioquia, Chocó, Valle del Cauca, Cauca, Nariño y en parte de los departamentos de Risaralda, Caldas y Quindío (viejo Caldas).

${ }^{30}$ La provincia de Ocaña agrupa municipios como Ábrego, Hacarí, Convención, Teorama, San Calixto, La Playa, El Carmen, El Tarra, entre otros, donde el voseo es el habla común. Es curioso, no obstante, que Flórez, Luis; Montes, José Joaquín y FIGUEROA, Jennie (1969). El español hablado en el departamento del Norte de Santander. Datos y observaciones. Publicaciones del Instituto Caro y Cuervo XXVIII. Bogotá, mencionen que en poblaciones como Chitagá, Bochalema, Pamplona, Cúcuta y Villa del Rosario se hablaba el voseo pronominal y el verbal, como ocurría en Ocaña, Ábrego y El Carmen. Cabe anotar que la investigación liderada por académicos del Instituto Caro y Cuervo se realizó en la década de los 60, cuando en la región aún era mayoría la población rural que la urbana. Quizás el crecimiento urbano que, según el Programa de las Naciones Unidas para el Desarrollo, Misión Social, Departamento Nacional de Planeación. Informe de Desarrollo Humano de 
la identidad de esta región reconocido en el territorio colombiano, ni al voseo verbal de algunos pueblos de la Guajira. ${ }^{31}$

En Venezuela la población es mayoritariamente tuteante, salvo en los estados de Zulia, Lara y Yaracuy. En el estado de El Zulia el voseo pronominal $\mathrm{y}$ verbal diptongado (vos compráis) se enmarca en la norma culta y, al igual que en la región camba de Bolivia, se constituye en un elemento identitario de orgullo regional. En los otros estados, Lara y Yaracuy, el voseo se concibe como propio de las clases de bajo nivel educativo.

En Ecuador subsiste el voseo pero con combinaciones caóticas de acuerdo con la región. Por ejemplo, en el norte, en la población de Esmeraldas, el voseo es el habla común en todas las clases sociales, mientras que en la sierra se mezclan las formas tuteantes y voseantes, en las zonas rurales se adoptan las terminaciones en $-i(s)$ típicas del voseo chileno, y en la costa el voseo es de tipo pronominal y verbal.

\section{El voseo en Centroamérica y el Caribe}

En Centroamérica y el Caribe se alterna entre el voseo y el tuteo en el trato informal, pero se mantiene el ustedeo como fórmula para el trato formal y respetuoso. Los países voseantes son Guatemala, El Salvador, Honduras, Nicaragua y Costa Rica, donde el voseo es un fenómeno general en todas las clases sociales. En Costa Rica predomina el voseo como norma culta, en tanto que el tuteo tiene connotación de pedantería. En El Salvador, Honduras y Nicaragua, el voseo -que suele ser pronominal y verbal- se produce en el trato familiar, el tuteo se utiliza para el tratamiento de formalidad intermedia y el ustedeo para la comunicación formal entre personas. En Guatemala el tú es considerado para afeminados y hay quienes piensan que el vos no es socialmente correcto para la mujer.

En Puerto Rico y República Dominicana no existen rastros del voseo. En México, Panamá y Cuba, por su parte, la mayoría de sus habitantes tutean, pero en algunas regiones el trato familiar se desarrolló con el vos pronominal y verbal.

\footnotetext{
Colombia. (1998): TM editores. Impreso en Colombia, se empieza a acelerar en los 70, y condiciones geográficas e influencias culturales que aún faltan por investigar, pudieron contribuir para que unos municipios optaran por el trato respetuoso del ustedeo (Chitagá, Bochalema, Pamplona, Cúcuta y Villa del Rosario) en lugar del voseo.

${ }^{31}$ En algunos pueblos de la Guajira se combina caóticamente el tuteo pronominal con el voseo verbal diptongado (tú tenéi, ustedes tenéi), muy similar al que se habla en Chile, el estado del Zulia en Venezuela donde comparten frontera, y en las regiones españolas de Andalucía occidental y Canarias (ustedes hacéis, ustedes os sentáis).z
} 
Ese es el caso del territorio comprendido entre Camagüey y Contramaestre y Baire en Cuba, donde prevalece el voseo pronominal y el verbal diptongado (vosabéi - vos sabéis); y en el norte de Panamá se alterna el tuteo con un voseo pronominal y verbal diptongado por limitar con Costa Rica.

En México sólo vosean en los estados de Chiapas y Tabasco -pero lo hacen los indígenas, personas de escasa formación y en el registro familiar de las personas cultas-, debido a que esas regiones dependieron durante el tiempo colonial no del virreinato, sino de la Capitanía General de Guatemala. ${ }^{32}$

\section{Reflexiones sobre el uso y el Desuso del Voseo en la Educación y en los Medios de Comunicación}

Actualmente el vos y los verbos monoptongados son la forma extendida de comunicación en gran parte de América Latina y el Caribe, sin embargo, es más frecuente que se emplee en el habla popular y no en la culta. Por ejemplo, es usual que el voseo se produzca para connotar confianza y cercanía entre dos personas de la misma condición social y educativa o de un superior a un inferior.

El usted, por su parte, se usa fundamentalmente en cuatro ocasiones: (1) para dirigirse a una persona que ostenta un rango, autoridad o jerarquía; (2) para entablar una conversación con personas mayores; (3) para comunicarse con alguien que se acaba de conocer; y (4) para demostrar enfado o indiferencia. Claro está que a medida que el contacto es mayor, lo más corriente es que se reemplace el ustedeo por el voseo, o que en las relaciones familiares, cuando el hijo se dirige a los padres o viceversa, se prefiera el vos y no el usted.

Lo extraño es que a pesar de que el voseo es de habla extendida, el sector educativo y los medios de comunicación, tanto en la publicidad como en los programas, los locutores y periodistas se inclinen por el usted. Esto no ocurre en los medios de comunicación de Argentina, Paraguay y Costa Rica, a los que les hemos efectuado seguimiento, y en el ámbito académico de los argentinos. Es más, escritores como el argentino Jorge Luis Borges (1899-1935), el colombiano Tomás Carrasquilla (1858-1940), el nicaragüense Ernesto Cardenal (1925), el uruguayo Mario Benedetti (1920) y el argentino Julio Cortázar, lo utilizan en sus obras. En los tangos de Carlos Gardel, las canciones del cantante colombiano Juanes y en la comedia argentina No sos vos soy yo, el voseo es el trato predominante.

${ }^{32}$ Ibídem, p. 11. 
Entonces, si existe un respaldo histórico, literario y lingüístico y si es el habla frecuente de la gente de los pueblos, puesto que constituye para de su propia identidad, por qué en algunas regiones tradicionalmente voseantes se enseña el tú y el usted con sus respectivas conjugaciones verbales como la única forma de comunicación del castellano y por qué sus medios de comunicación continúan reproduciendo expresiones que no son las habituales de las personas, en detrimento de la transmisión de la propia identidad.

En el ámbito educativo, como lo sugiere García, ${ }^{33}$ las políticas de este sector tradicionalmente han homogenizado la cultura de los pueblos, a través de la transmisión de la lengua y las hablas hegemónicas desconociendo las lenguas y expresiones corrientes de los pueblos en las que subyacen fuertes lazos de identidad y cooperación. Por su parte, la Unesco etxea et al. ${ }^{34}$ toman el enfoque de la educación global de la educación para el desarrollo para advertir sobre la necesidad de tener en cuenta la diversidad cultural, la democracia y la participación social en la formación de las personas. En este contexto, la escuela funge como el espacio en el que se construyen identidades a partir del conocimiento del legado cultural, particularmente en este caso del habla y la lengua, para la construcción de seres humanos que revaloran la historia e las interacciones sociales de su comunidad.

En el ámbito de los medios de comunicación, la explicación para evitar el reconocimiento del habla particular puede hallarse en la lectura que se hace de los códigos de ética periodística y en las recomendaciones del protocolo internacional. Javier Darío Restrepo y María Teresa Herrán, ${ }^{35}$ autores del libro Ética para periodistas, señalan que el comunicador debe tener una relación amigable aunque respetuosa con las fuentes para evitar que la información esté influida por afectos, amiguismos, censuras o autocensuras. En el caso del protocolo internacional, se estima conveniente emplear el usted para connotar diplomacia y respeto hacia las personas cuando son objeto de mención o reconocimiento en actos públicos, la mayoría de ellos solemnes.

\footnotetext{
${ }^{33}$ GARCÍA, María del Socorro. (2005): "Educación e identidad: redefinición de la identidad nacional a través de la educación”, en Quivera, año/vol. 7, número 002. México, Universidad Autónoma del Estado de México, pp. 326-354.

${ }^{34}$ UNESCO ETXEA \& COORDINADORA DE ONGD DE LA COMUNIDAD AUTÓNOMA VASCA. (2004): Cuaderno de trabajo de educación para el desarrollo. Coordinador: Itziar Caballero González. Edición UNESCO etxea, Servicios Redaccionales Bilbaínos, S. L. (SRB).

${ }^{35}$ HERRÁN, María Teresa y RESTREPO, Javier Darío. (1995): Ética para periodistas, Bogotá, Tercer Mundo, editores, p 34.
} 
Lo curioso es que la forma extendida del usted también se utiliza en la publicidad, bien sea radial, televisiva, escrita o virtual, a pesar de que los cánones publicitarios señalan que la venta de una idea, producto o servicio debe apelar al habla común de las gentes.

En todo caso es legítimo que los medios de comunicación empleen el usted si quieren enfatizar el respeto hacia la fuente y el público, sin embargo, no siempre por ser respetuoso y formal se está comunicando adecuadamente el mensaje a un interlocutor o receptor o se está logrando una interacción productiva con él. Lo que queremos decir es que en la relación de los media y el público se tiene muy en cuenta el marco cultural tanto de emisor como de receptor y en la medida en que hay más elementos comunes entre los dos más fluida y efectiva es la comunicación.

Wilbur Schramm (1954) lo da entender en uno de sus modelos de la comunicación en el que incluye el campo de la experiencia compartida entre comunicantes y receptores.

Ilustración 1. Modelo de comunicación de Wilbur Schramm

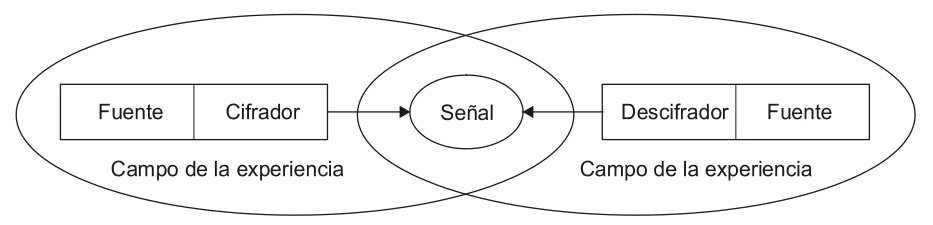

Fuente: Zabaleta ${ }^{36}$ parcialmente adaptado.

En vista de que la tarea educativa no puede entenderse sin una acción comunicativa, ${ }^{37}$ el modelo tiene aplicación tanto en la labor educativa como en el trabajo de difusión de los medios masivos, para facilitar la comprensión de los mensajes a partir de un campo común (señal) de los actores en dichos procesos. Lo que Schramm quiere enfatizar es que entre más cercano sea el campo de la experiencia o más elementos comunes se compartan de la cultura, más posibilidades existen de que entre comunicantes y receptores se realice un

\footnotetext{
36 ZABALETA, Iñaki. (2005): Teoría, técnica y lenguaje de la información en televisión y radio. Sistemas digitales y analógicos. Bosch, comunicación. Barcelona, Impreso en Barcelona.

37 DE FONTCUBERTA, Mar. (2001): “Comunicación y educación: una relación necesaria”, en Cuadernos de información, $N^{o} 14$, pp. 139-147.
} 
diálogo productivo. ${ }^{38}$ Del mismo modo, si en la educación y en la comunicación periodística y publicitaria se interactúa bajo un elemento común (lenguaje, idioma $\mathrm{y}$, finalmente, el habla) más oportunidades hay que el mensaje sea entendido y respondido.

En este caso, el voseo es un elemento muy importante de la identidad de los latinoamericanos por lo cual debe ser incorporado paulatinamente a la enseñanza en las escuelas, como lo están los pronombres y conjugaciones del castellano tradicional. Esto significa que deben buscarse nuevas metodologías para el estudio del fenómeno lingüístico del voseo desde un punto de vista académico y no sólo anecdótico.

En el mundo de los medios de comunicación, no significa que de un momento a otro en los noticieros, magacines o programas de entrevistas se sustituya el ustedeo por el voseo, sino que este último se puede emplear en algunos contextos en que el entrevistado y la naturaleza del programa lo permitan. Por ejemplo, en magacines, espacios de variedades, en temas distendidos y en la misma conversación entre los periodistas se puede incorporar el voseo para que los contenidos sean más familiares. Ahora bien, esa recomendación no es valedera cuando la seriedad de la temática que se aborda o el origen del protagonista requiera un distanciamiento formal y objetivo con la fuente y el tópico en cuestión, lo cual se logra con el uso del usted.

En la publicidad la situación es distinta. Si tenemos en cuenta que un mensaje es efectivo cuando la codificación del mensaje se hace mediante símbolos cuyo significado pertenezca al marco cultural entre los participantes del proceso de la comunicación $o$, simplemente, sea de fácil interpretación por el receptor, ${ }^{39}$ entonces lo más conveniente es que los publicistas se valgan del habla común de una región para expresar y crear emociones, que incentiven la venta de un producto, idea o servicio.

\section{CONCLUSIONES}

El voseo es el otro castellano de América, tardíamente reconocido por la Academia de la Lengua Española y la Asociación de Academias de la Lengua, que tiene una impronta muy arraigada en las $2 / 3$ partes de los habitantes de

\footnotetext{
38 TOUSSAINT, Florence. (1992): Crítica de la Información de Masas. Serie: temas básicos. Área: taller de lectura y redacción. México, Editorial Trillas, p. 56.

39 ORTEGA, Enrique. (1997): La comunicación publicitaria. Madrid, Ediciones

Pirámide, p78.
} 
Latinoamérica. El estudio de esta forma de expresión tan sólo se empieza a vislumbrar, motivado por el reconocimiento realizado por el Diccionario panhispánico de dudas y por millones de personas que sin ningún complejo utilizan el voseo pronominal y verbal para dirigirse a sus semejantes.

El voseo es una forma de expresión tan diversa y rica en América Latina, que resulta imposible presentarla como una unidad lingüística. Todo apunta a que las condiciones geográficas y culturales influyen notablemente para que el voseo sea tan divergente entre Chile, Bolivia, Colombia y otras naciones, e incluso en el interior de esos mismos territorios.

El modelo de voseo más conocido es el argentino porque fue el primer país que lo reconoció en el habla culta y popular y porque después de su independencia en 1810 hubo un fuerte movimiento civil que pregonó la independencia lingüística de Argentina con respecto a la española. Aun así, el voseo se encuentra extendido por América Latina y el Caribe y empieza a ser concebido como un fenómeno multicultural desde el cual se pueden indagar las relaciones interpersonales y de poder, así como la influencia de las condiciones geográficas en la configuración de la cultura que acontecieron en la época colonial.

Es curioso también que siendo el voseo un elemento fundamental de la cultura latinoamericana, en la educación reglada y en algunos medios de comunicación de la región no lo utilicen con frecuencia a la par con el tuteo y el ustedeo, a pesar de que evidencias teóricas y conceptuales apoyan el uso del habla común de las gentes para que el proceso comunicativo sea más fluido y efectivo.

En este artículo, por tanto, se propone la incorporación paulatina del voseo en la enseñanza que se imparte en escuelas y en algunos géneros de programas de los medios de comunicación (magacines, programas de entrevistas y de variedades) de las regiones que lo emplean en la cotidianidad, con el fin de promover y fortalecer los lazos identitarios. Para ello acogemos el modelo de Wilbur Schramm porque permite facilitar la comprensión del mensaje a partir precisamente del campo de la experiencia común que, en este caso, gira en torno al habla de los pueblos.

\section{Archivo}

\section{FUENTES}

Real Academia de la Lengua y Asociación de Academias de la Lengua Española.

\section{Entrevistas}

Greta Frankenfeld; biólogo marino chileno, Guillermo Aravena; trabajador uruguayo Rubén Ruiz; economista nicaragüense, Ana Cristina Rostrán Molina y el trabajador boliviano Dino Vargas.en Bilbao (España) durante el año 2006. 


\section{REFERENCIAS}

BOLETÍN DE LAACADEMIAARGENTINADE LETRAS XLVII. (1982): Buenos Aires, Academia Argentina de Letras.

CARRICABURO, Norma Beatriz. (2000): “Algunas peculiaridades morfosintácticas del Español de la Argentina. Español actual”, en Revista de español vivo, edición 74. Argentina, pp. 25-36.

DE FONTCUBERTA, Mar. (2001): “Comunicación y educación: una relación necesaria”, en Cuadernos de información No 14. Chile, Universidad pontificia de Chile.

FLÓREZ, Luis; MONTES, José Joaquín yFIGUEROA, Jennie. (1969): El español hablado en el departamento del Norte de Santander. Datos y observaciones. Bogotá, Publicaciones del Instituto Caro y Cuervo XXVIII.

VAQUERO de Ramírez, María. (1996): "El español de América”. Tomo II, en Cuadernos de Lengua Española, Madrid, Arco Libros S.A

GARCÍA, María del Socorro. (2005): "Educación e identidad: redefinición de la identidad nacional a través de la educación”, en Quivera, Vol. 7, No 002. México, Universidad Autónoma del Estado de México.

HERRÁN, María Teresa y RESTREPO, Javier Darío. (1995): Ética para periodistas. Santa Fe de Bogotá, Tercer Mundo, editores.

LAPESA, Rafael. (1970): Las formas verbales de segunda persona y los orígenes del voseo. Actas del Tercer Congreso de Hispanistas. Coord. Por Carlos H. Magis. México

LAPESA, Rafael. (1980): Historia de la lengua española. Madrid, España, Editorial Gredos S.A.

LAPESA, Rafael. (1981): El español de América, en Lapesa, España, consejo superior de investigaciones científicas.

MALBERG, B. (1970): La América hispanohablante. Madrid, ediciones Itsmo.

ORTEGA, Enrique. (1997): La comunicación publicitaria. Ediciones Pirámide. Impreso en Madrid, España.

PROGRAMADE LAS NACIONES UNIDAS PARAELDESARROLLO(PNUD), MISIÓN SOCIAL, DEPARTAMENTO NACIONALDE PLANEACIÓN. (1998): Informe de Desarrollo Humano de Colombia. Colombia, TM editores.

REAL ACADEMIA ESPAÑOLA. (2001): Diccionario de la lengua española. Vigésima segunda edición, España.

Rhela. Vol. 14. Año 2009, pp. 267 - 288 
REAL ACADEMIAESPAÑOLA \&ASOCIACIÓN DE ACADEMIAS DE LALENGUA ESPAÑOLA. (2005): Diccionario panhispánico de dudas. Madrid, Santillana Ediciones Generales, S. L.

SÁBATO, Ernesto. (1966): "El Voseo", en Revista Cuaderno Cultural, del Departamento Cultural de la Embajada Argentina en Madrid. Año 4, $n^{\circ}$ 6, España.

TOUSSAINT, Florence. (1992): Crítica de la Información de Masas. Serie: temas básicos. Área: taller de lectura y redacción. México, Editorial Trilla.

URDANETA, I.P. (1981): Historia y geografia hispanoamericana del voseo. Caracas, La Casa de Bello.

UNESCOETXEA\& COORDINADORADE ONGDDE LACOMUNIDADAUTÓNOMA VASCA. (2004): Cuaderno de trabajo de educación para el desarrollo. Coordinador: Itziar Caballero González. Edición UNESCO etxea. Servicios Redaccionales Bilbaínos, S. L. (SRB).

ZABALETA, Iñaki. (2005): Teoría, técnica y lenguaje de la información en televisión y radio. Sistemas digitales y analógicos. Bosch, comunicación. Espina, Impreso en Barcelona.

ZAMORA, Alonso. (1974): Dialectología española. Madrid, Editorial Gredos, S.A.

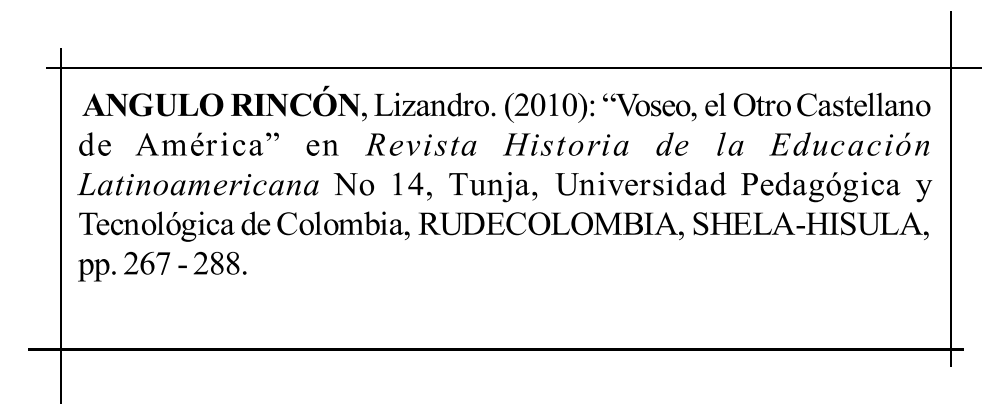

Rhela. Vol. 14. Año 2009, pp. $267-288$ 